\title{
RESEÑAS
}

Carlos de la Isla, De la perplejidad a la utopía, 1998, México, Ediciones Coyoacán/ITAM, 240 pp.

Los 21 textos que este libro recoge, escritos entre 1981 y 1998, se agrupan en dos secciones temáticas: "Educación y universidad" y "Ética, ciencia y sociedad". En conjunto, estos ensayos, conferencias y reseñas, antologados hace casi veinte años, ofrecen a la consideración del lector contemporáneo dos asuntos de no escaso interés.

En primer lugar, el libro hace un diagnóstico filosófico y sociológico de la posmodernidad, es decir, del paradigma cultural que, en los campos político, económico, tecnológico e inclusive académico, emergió en Occidente en las décadas finales del siglo XX —un paradigma que hoy, con la irreversible y omnímoda digitalización del mundo, muestra sus rasgos con toda claridad. En este orden de cosas, el hecho de que el autor elabore sus reflexiones sobre la cultura occidental desde un país del "Extremo Occidente", y que lo haga teniendo siempre a la vista la situación geopolítica de México, confiere a los textos compendiados en De la perplejidad a la utopía un valor adicional: la posibilidad de comprender, en el contexto de naciones especialmente vulnerables, aquejadas de precariedad institucional y, sobre todo, de desigualdad social, los efectos más nocivos de una mutación civilizacional gestionada desde instancias transnacionales de enorme poder político y económico.

En segundo lugar, el libro deja ver el perfil intelectual y moral de un destacado e incansable profesor del Departamento de Estudios Generales del ITAM, humanista de formación clásica, socialmente comprometido con los valores del liberalismo igualitario y comprometido no solo en el plano del pensamiento teorético, sino en el de la materialización institucional de esa agenda política en un ámbito como el mexicano, en el que la prevalencia de la desigualdad 
obedece a motivos sistémicos, sí, pero también a vicios privados convertidos en prácticas públicas, vicios y prácticas que el autor no se cansa de denunciar.

A De la Isla le interesan menos la variopinta nomenclatura y los diversos conceptos maestros que se han utilizado para designar al nuevo paradigma (posmodernidad, posindustrialismo, quiebra del Estado de bienestar, etc.), que la evaluación de las consecuencias sociales y personales que su implantación ha provocado en algunas de las instituciones más representativas de la era moderna: el Estado-nación, la empresa privada y, sobre todo, la universidad. En casi todos los ensayos, e incluso en algunas de las reseñas, el autor analiza con lucidez y detalle las tensiones y dilemas éticos que aquella mutación cultural generó (y sigue generando) en la comunidad académica, así como en el funcionariado que gestiona las políticas económicas nacionales y también en la cúpula empresarial.

De la perplejidad a la utopía no es solamente el título del libro, sino también una expresión que testimonia una experiencia de años de lectura (tanto de libros como de fenómenos sociales), ejercicio docente y comunicación académica. Así, el tránsito desde la perplejidad producida por la que Jean-François Lyotard llamó "crisis de los metarrelatos" de la modernidad (y por el concomitante debilitamiento de las instituciones garantes del Estado de bienestar), hacia una resignificación y reivindicación de los valores que tales relatos e instituciones protegían, adquiere en el pensamiento de De la Isla un cariz utópico, siempre y cuando no se malinterprete la utopía como la proyección fantasiosa de aspiraciones irrealizables, sino como un faro o como una idea reguladora kantiana, cuya modesta pero importante función consiste en guiar la praxis social concreta por derroteros diferentes a los del nihilismo y el mercantilismo posmodernos. En "Educación para la libertad" (1991), el autor expuso con determinación y claridad su proyecto pedagógico utópico:

Educar para la libertad es afirmar la utopía permanente que consiste en la denuncia y el anuncio: denuncia de todo lo que haya que condenar en todos los niveles, desde el saber falso y el dogmatismo hasta las más sofisticadas falsificaciones de las estructuras sociales, políticas y económicas. Pero anuncio también de los proyectos humanos construidos con la imaginación y la honestidad de la reflexión libre frente a la meta de un desarrollo pluridimensional. [p. 97]

En otras palabras, al invitar al lector a acompañarlo en su paso de la perplejidad a la utopía, el autor intenta trazar un camino, o al menos señalar un 
rumbo, para dirimir este dilema: ¿son conciliables las expectativas liberal-igualitarias sobre el bien común, fundadas en las estructuras éticas, intelectuales y sociopolíticas de la modernidad, con las exigencias de rendimiento económico a todo trance que, desde el mundo de los negocios y en alianza con el eficientismo técnico, han permeado desde fines del siglo XX prácticamente todos los espacios sociales?

A 19 años de la publicación del libro, las condiciones de enunciación del dilema recién mentado son otras. Tal vez hoy habría que reformularlo así: ¿cómo hacer que las expectativas del liberal-igualitarismo estén siquiera insertas en la agenda política de un mundo reglado por la competitividad económica? Aun cuando la hostilidad del contexto institucional se ha acentuado, incluso al grado de que hoy sea moneda corriente pensar que las reivindicaciones sociales deben revestirse de carácter mercantil para poder ser gestionadas en forma de políticas públicas, la disyuntiva que plantea De la Isla permanece vigente.

De acuerdo con el autor, la manera adecuada de enfrentar ese dilema consiste en promover una ética y una praxis comunitarias fundadas en la responsabilidad de los individuos para con la procuración del bien común. El impulso y la asunción de esa línea de conducta deben partir de la comunidad universitaria y del fortalecimiento de la universidad como institución evaluadora y orientadora de la acción social, como instancia crítica de los mecanismos de dominación y, al mismo tiempo, atenta a prevenir su reproducción servil por parte de los profesionistas que forma. Nuestro autor es, en este orden de cosas, un maximalista ilustrado prosocial, que confía en la misión reflexiva y clínica de la educación superior, tal como se infiere de una de las muchas declaraciones de principios dispersas a lo largo del libro: "el compromiso ineludible de la universidad es ser conciencia crítica de la sociedad y, por tanto, elucidante y liberadora [...] la universidad traiciona su compromiso social cuando deja de ser el baluarte en contra de la dominación y termina ella misma dominada y aun dominadora" (p. 74).

De la Isla supo con oportunidad y lucidez, desde principios de la década de 1980, cuando menos, que la universidad comenzaba a experimentar un proceso de desecamiento tecnocrático. En el contexto mexicano, supo ver que la instauración de ese proceso era cómplice de un autoritarismo político muy poco ilustrado. Ante ese panorama, De la Isla propuso una vehemente defensa de la actividad docente, entendida como práctica mayéutica y dialógica, pero también insistió en la necesidad de diseñar programas académicos capaces 
de proveer una formación humana integral — no solo un entrenamiento o una capacitación - y de fomentar un espíritu ilustrado en los estudiantes, en la medida en que a ellos, futuros profesionistas, agentes económicos y tomadores de decisiones políticas, correspondería trasladar esos valores adquiridos, o bien, reforzados en la universidad, a otras instituciones, reguladoras de la vida pública.

En este mismo sentido, el autor tocó el nervio del asunto educativo en un ensayo de 1989, "Educación y democracia": "Sin duda, la máxima dificultad para construir y difundir la educación democrática es la rigidez antidemocrática de las relaciones reales de la existencia social” (p. 94). Ante este difícil panorama, el autor apostó por la defensa de los valores del humanismo clásico, entendiendo por clásico un adjetivo que señala ciertas virtudes: la defensa de la dialéctica por encima de la erística, el entendimiento de lo político como conciliación de singularidades heterogéneas a partir de un sustrato de intereses comunes, la promoción del espíritu crítico a garante de que la toma de decisiones sobre el bien común no derive en imprudencia, en autoritarismo o en un híbrido de ambos.

Para prevenir e inclusive mitigar esos males, el autor recomienda enseñar a los universitarios a pensar críticamente y a trasladar ese ejercicio intelectual fuera de las aulas, con el fin de volver prudente y reflexivo otro ejercicio, el de los poderes político y económico. De la Isla sabe lo difícil que puede ser el uso del criterio cuando se trata de refrenar los intereses de los más fuertes; por ello, su recuperación del concepto de utopía no es idealista. Lejos de esperar "que los reyes filosofen ni que los filósofos se conviertan en reyes", ${ }^{1}$ nuestro autor sugiere, de igual manera que Kant en el "Artículo secreto para la paz perpetua", que "las máximas de los filósofos sobre las condiciones que hacen posible la paz pública deben ser tomadas en cuenta por los Estados preparados para la guerra", 2 si bien en De la perplejidad a la utopía se trata de la guerra contra la ignorancia, el servilismo ilustrado y la desigualdad.

\section{GABRIEL ASTEY}

Departamento Académico de Lenguas, ITAM

${ }^{1}$ Immanuel Kant, La paz perpetua, 2007, Madrid, Mestas, trad. de José Loya, p. 61.

${ }^{2}$ Ibid., p. 59. 